\title{
Variables influencing cork thickness in spanish cork oak forests: A modelling approach
}

\author{
Mariola SÁNCHEZ-GonZÁlEZ*, Rafael CALAMA, Isabel CAÑEllaS, Gregorio MonTERo \\ Centro de Investigación Forestal, INIA, Ctra. de La Coruña, km 7,5, 28040 Madrid, Spain
}

(Received 27 March 2006; accepted 15 June 2006)

\begin{abstract}
In this study, we evaluate the influence of different variables on cork thickness in cork oak forests. For this purpose, first we fitted a multilevel linear mixed model for predicting average cork thickness, and then identified the explanatory covariates by studying their possible correlation with random effects. The model for predicting average cork thickness is described as a stochastic process, where a fixed, deterministic model, explains the mean value, while unexplained residual variability is described and modelled by including random parameters acting at plot, tree, plot $\times$ cork harvest and residual within-tree levels, considering the spatial covariance structure between trees within the same plot. Calibration is carried out by using the best linear unbiased predictor (BLUP) theory. Different alternatives were tested to determine the optimum subsample size which was found to be appropriate at four trees. Finally, the model was applied and its performance in the estimation of cork production was tested and compared with the cork weight model traditionally used in Spain.
\end{abstract}

cork thickness / mixed model / calibration / Quercus suber L.

Résumé - Variables influençant l'épaisseur du liège dans les forêts de chênes-lièges espagnoles : une proposition de modélisation. Dans cette étude, nous avons mesuré l'influence de diverses variables sur l'épaisseur du liège des forêts de chênes-lièges. Dans ce but nous avons d'abord appliqué un modèle linéaire mixte pour prédire l'épaisseur moyenne du liège, et on a alors identifié les co-variables explicatives pour expliquer leur possible corrélation avec des effets aléatoire. Le modèle prédisant l'épaisseur moyenne du liège peut être décrit comme un processus stochastique où un modèle fixe et déterministe explique la valeur moyenne, tandis qu'une variabilité résiduelle inexpliquée est décrite et modélisée par l'inclusion de paramètres aléatoires relevant de la parcelle, de l'arbre, de la récolte de liège par parcelle et aux niveaux résiduels des arbres prenant en compte la covariance de la structure spatiale entre les arbres d'une même parcelle. Le calibrage a été réalisé en employant la théorie BLUP (Best linear unbiased predictor ou Meilleur prédicteur linéaire non biaisé) On a essayé différentes options pour trouver la dimension optimale de l'échantillon et on a trouvé qu'il était opportun d'utiliser quatre arbres par parcelles. Finalement le modèle a été appliqué pour calculer la production de liège et a été comparé avec le poids de liège obtenu avec le modèle employé d'habitude en Espagne.

épaisseur du liège / modèle mixte / calibrage / Quercus suber L.

\section{INTRODUCTION}

Cork production constitutes a basic source of income in cork oak stands prevailing in pre-coastal and coastal regions of the Mediterranean Basin [11,31]. Spain is the second major cork producing nation with 510000 ha (23\% of the world's total) and an annual production of $110000 \mathrm{t}$ (32\% of the world's total) [36]. Although the main use of these stands is cork production, they are also efficiently exploited for other uses which include hunting, cattle grazing, acorn production, firewood, or biological and landscape diversity.

The management of these cork oak stands is oriented towards cork production, in particular towards the maintenance of cork quality. Cork quality depends on three main characteristics: cork thickness, cork porosity and the presence of defects such as insect galleries or wood inclusions which may appear occasionally [31]. Cork thickness defines the usability and the value of the cork for industrial purposes. Natural cork stoppers

* Corresponding author: msanchez@inia.es are the most valuable product and mainstay of the cork industry. Cork planks with a thickness over $27 \mathrm{~mm}$ are suitable for the production of stoppers, and the best yield is obtained with a thickness of between 27 and $33 \mathrm{~mm}$ [18].

Despite its economic and industrial importance, research in relation to cork thickness has been scarce. Vieira [45] studied the influence of age and debarking height on cork thickness. Montero and Vallejo [30] used data from 100 trees of different sizes and stripped heights to study cork thickness variation along the bole. Cork thickness has seldom been modelled, due to its great complexity and variability. González-Adrados et al. [18] developed an equation for predicting total cork thickness at debarking time where the independent variable was cork thickness one year before stripping. A similar approach follows the cork thickness sub-model included in the SUBER model [42], a management oriented growth and yield model, developed in Portugal for open cork oak woodlands.

Among the numerous factors which appear to influence cork thickness we might mention genetic variability [14], site quality [29, 35], stand and single tree factors [5] as well as 
debarking factors $[30,45]$. Due to the fact that many of these factors are not easily controlled when modelling cork thickness, stochastic models seem to provide the most suitable approach, especially during the first stages of modelling [25].

Cork thickness data are usually taken at each cork harvest from trees growing in plots. This hierarchical structure favours the use of a multi-level linear mixed approach. Mixed models include a fixed functional part, common to the whole population, and random components that allow us to divide and explain the different sources of stochastic variability which are not explained by the fixed part of the model. Another advantage of the mixed models is that they allow calibration of models for a specific location and period from a small additional sample of observations. The mixed model approach was proposed by Vázquez [44] for modelling single tree cork weight.

Empirical experience has shown that cork oak trees which produce good cork quality, tend to maintain this standard in successive strippings throughout their productive life [7]. In the same way, it has been observed that there are productive areas, where trees tend to have greater cork thickness, and that these areas retain their productivity level throughout the cycle. Finally, it is also possible to identify good and bad periods for cork thickness, probably due to climatic effects [45]. All these facts indicate that some unobservable tree factors (e.g., microsite or genetics), plot factors (ecological conditions or silviculture) or period effects (climatic conditions) affect tree cork thickness, even over long periods [29]. This allows us to calibrate cork thickness models for present and future cork harvests by introducing predicted stochastic effects into the model which are specific to each source of variability.

The main objective of this study is to determine the variables which influence cork thickness by identifying the different sources of variability detected in Spanish cork oak forests. For this purpose we developed a multilevel linear mixed model and evaluated the inclusion of ecological, stand and tree attributes as fixed effects to explain detected non explained variability at different levels (plot, tree, harvest). Calibration of the model from a small additional sample of observations was proposed as a practical approach for model utilization, and its accuracy in cork weight estimation was tested.

\section{MATERIAL AND METHODS}

\subsection{Study area and data}

The Natural Park of "Los Alcornocales" (Fig. 1), with an extension of 170025 ha is one of the most important cork producing areas in Spain and can be considered representative of Spanish cork oak forests [38]. The area has a mild Mediterranean climate with cool humid winters and warm-dry summers; the mean annual temperature is about $16-18{ }^{\circ} \mathrm{C}$ and the annual precipitation between 1000 and $1400 \mathrm{~mm}$ (depending on altitude). Precipitation is mainly concentrated between autumn and spring, originating a dry period in summer [10]. The soils are cambisols and luvisols (FAO) [12] which are quite developed.

Data for this study were collected in 47 circular permanent plots of $20 \mathrm{~m}$ radius established by the Forest Research Centre (CIFORINIA) in the Natural Park. All plots were established between 1988

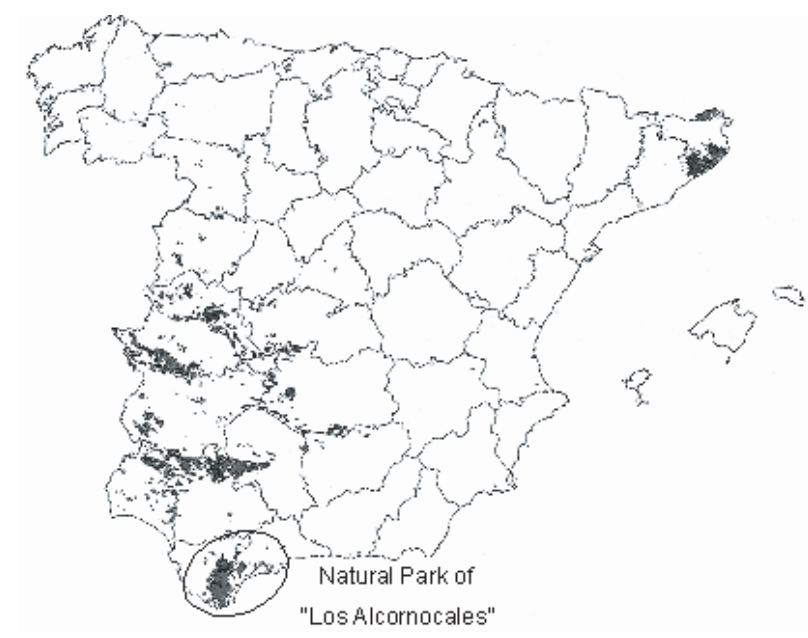

Figure 1. Distribution of Quercus suber L. in Spain and localization of the studied region.

and 1993 in regularly stocked stands covering a wide range of age and site conditions. In each plot, the first measurement was made at plot installation coinciding with a cork harvest. The second inventory was carried out at the time of the subsequent cork harvest (generally after a nine year period).

The variables measured at each inventory were: perimeter at breast height over and under cork, stripped height, cork weight and cork thickness measured at the upper and lower ends of the three biggest cork planks from each stripped tree. For each tree, average cork thickness was calculated as the average of these six cork thickness measurements. More recently, tree coordinates have been measured. Increment cores were not taken because they tend to be illegible [21], so individual tree age is unknown. The age of the plot was estimated using stem analysis data obtained near each plot in 2002 and the data from the historic management records compiled from the Management Plans and their subsequent Revisions [34]. Site index was calculated for each plot using the potential height growth model developed by Sánchez-González et al. [38].

From this data set, 10 plots including 254 trees were selected as a calibration data set. These plots were selected because measurements were only taken at one cork harvest. The rest of the observations (coming from two repeated measurements taken on 795 trees from 37 plots; totalling 1590 cork thickness observations) were used as the fitting data set.

Descriptive statistics of cork characteristics for both data sets are displayed in Table I.

\subsection{Identification of variables influencing cork thickness}

The process of identification of variables influencing cork thickness involved two stages. In the first stage, a multilevel linear mixed model was fitted, in order to characterize the variability structure and remove the effects of the spatial autocorrelation. In the second stage, the explanatory covariates were identified by studying the correlation between random effects and possible explanatory covariates. 
Table I. Characterisation of the fitting and calibration data set.

\begin{tabular}{|c|c|c|c|c|c|c|}
\hline & Variable & Mean & Min & $\operatorname{Max}$ & STD & $\mathrm{CV}(\%)$ \\
\hline \multirow[t]{3}{*}{ Fitting data 1 st harvest } & $\mathrm{cb}(\mathrm{mm})$ & 25.59 & 11.63 & 57 & 6.03 & 23.58 \\
\hline & $\mathrm{w}(\mathrm{kg})$ & 21.7 & 4.5 & 141 & 14.97 & 68.98 \\
\hline & $\operatorname{sh}(\mathrm{m})$ & 1.79 & 0.77 & 5.4 & 0.61 & 34.25 \\
\hline \multirow[t]{3}{*}{ Fitting data 2nd harvest } & $\mathrm{t} \mathrm{cb}(\mathrm{mm})$ & 26.28 & 9 & 57.34 & 6.05 & 23.03 \\
\hline & $\mathrm{w}(\mathrm{kg})$ & 24.49 & 2.5 & 142.5 & 17.19 & 70.18 \\
\hline & $\operatorname{sh}(\mathrm{m})$ & 2.14 & 0.78 & 5.4 & 0.75 & 35.11 \\
\hline \multirow[t]{3}{*}{ Calibration data } & $\mathrm{cb}(\mathrm{mm})$ & 29.41 & 11.25 & 57.53 & 7.6 & 25.85 \\
\hline & $\mathrm{w}(\mathrm{kg})$ & 22.43 & 3 & 67 & 12.57 & 56.05 \\
\hline & $\operatorname{sh}(\mathrm{m})$ & 1.81 & 0.83 & 4.2 & 0.57 & 31.76 \\
\hline
\end{tabular}

Min: Minimum; Max: maximum; STD: standard deviation; CV: coefficient of variation; cb: cork thickness (mm); w: tree cork weight $(\mathrm{kg})$; sh: stripped height (m).

\subsubsection{Cork thickness modelling}

The available fitting data set consists of a sample of cork thickness measurements taken twice from trees located within different plots. This hierarchical nested structure leads to lack of independence, since a greater than average correlation is detected among observations coming from the same tree, plot or cork harvest $[16,20]$.

In order to alleviate this, cork thickness is explained using a multilevel linear mixed model $[4,17,41]$, including both fixed and random components. In this model, systematic patterns of non explained variability, detected between plots, between trees, and within a given plot or within a given tree between different cork harvests were accounted for by including random parameters, affecting the intercept of the model, specific at those levels. A general expression for the multilevel linear mixed model proposed, defined for the cork thickness value $(\mathrm{cb})$ measured on the $j$-th tree within the $i$-th plot, in the $k$-th cork harvest, is:

$$
\mathrm{cb}_{i j k}=\mathrm{x}_{i j k} \beta+\mathrm{u}_{i}+\mathrm{v}_{i j}+\mathrm{w}_{i k}+\mathrm{e}_{i j k}
$$

where $\mathrm{x}_{i j k}$ is $1 \times \mathrm{p}$ design vector containing covariates explaining the response variable, $\beta$ is the $p \times 1$ vector of fixed parameters in the model; $\mathrm{u}_{i}, \mathrm{v}_{i j}$, and $\mathrm{w}_{i k}$ are random components specific for each plot, tree and plot $\times$ cork harvest, realizations from univariate normal distributions with mean zero and variance $\sigma_{\mathrm{u}}^{2}, \sigma_{\mathrm{v}}^{2}$, and $\sigma_{\mathrm{w}}^{2}$ respectively, $\mathrm{e}_{i j k}$ is a residual error term, with mean zero and variance $\sigma_{\mathrm{e}}$. Inclusion of a common cork harvest effect was not considered, since cork growth periods were different for different plots.

When fitting the framework, the available cork thickness outcomes were $\mathrm{N}$ (1590), obtained from $j$ trees $\left(j=1\right.$ to $\mathrm{N}_{i j}$, with $\mathrm{N}_{i j}$ ranges from 11 to 42 trees per plot), growing within plot $i(i=1$ to 37$)$ in two different cork harvests $(k=1,2)$. For the complete data set, the general expression of the model is [40]:

$$
\mathrm{cb}=\mathrm{X} \beta+\mathrm{Zb}+\mathrm{e}
$$

where $\mathrm{cb}$ is the $\mathrm{N} \times 1$ vector containing the complete database of cork thickness outcomes; $\mathrm{X}$ is a $\mathrm{N} \times \mathrm{p}$ design matrix with rows $\mathrm{x}_{i j k} ; \beta$ is the $\mathrm{p} \times 1$ vector of fixed parameters in the model; $\mathrm{Z}$ is a $\mathrm{N} \times \mathrm{q}$ design matrix, including zeroes and ones; $\mathrm{b}$ is a $\mathrm{q} \times 1$ vector of random components, including in this analysis 795 tree components $\mathrm{v}_{i j}, 74$ plot $\times$ cork harvest components $\mathrm{w}_{i k}$ and 37 plot components $\mathrm{u}_{\mathrm{i}}$; $\mathrm{e}$ is a $\mathrm{N} \times 1$ vector of residual tree within cork harvest terms.

Vector $\mathbf{b}$ is assumed to be distributed following a multivariate normal distribution with mean zero and variance matrix $\mathbf{D}$, a $\mathrm{q} \times \mathrm{q}$ block diagonal matrix whose components are matrices $\mathbf{D}_{\mathrm{u}}, \mathbf{D}_{\mathrm{v}}$ and $\mathbf{D}_{\mathrm{w}}$. As a first approach, we assumed independence between random components specific to different sampling units (plot, tree, harvest) at the same hierarchical level, so $\mathbf{D}_{\mathrm{u}}, \mathbf{D}_{\mathrm{v}}$ and $\mathbf{D}_{\mathrm{w}}$ are diagonal matrices with dimensions equalling the number of plots (37), trees (795) and plot $\times$ cork harvests (74) being considered in the analysis, and diagonal values of $\sigma_{\mathrm{u}}^{2}, \sigma_{\mathrm{v}}^{2}$ and $\sigma_{\mathrm{w}}^{2}$. In subsequent steps different structures for $\mathbf{D}_{\mathrm{u}}$ and $\mathbf{D}_{v}$, were evaluated in terms of -2 times $\log$ likelihood statistic by considering the spatial covariance between observations coming from different plots or coming from different trees within the same plot:

- Exponential covariance:

$$
\sigma_{12}=\sigma^{2}\left[\exp \left(\frac{-\mathrm{d}_{12}}{\rho}\right)\right]
$$

- Gaussian covariance:

$$
\sigma_{12}=\sigma^{2}\left[\exp \left(\frac{-\left(\mathrm{d}_{12}^{2}\right)}{\rho^{2}}\right)\right]
$$

- Power covariance:

$$
\sigma_{12}=\sigma^{2}\left[\rho^{\mathrm{d}_{12}}\right]
$$

Where $\sigma_{12}$ indicates covariance between two observations, $\sigma^{2}$ indicates the variance component (at plot or tree level), $\mathrm{d}_{12}$ the distance between the two trees or plots, and $\rho$ is the correlation parameter.

Finally, vector $\mathbf{e}$ is distributed following a multivariate normal distribution with mean zero and variance matrix $\mathbf{R}$, normally a $\mathrm{N} \times \mathrm{N}$ diagonal matrix, with elements $\sigma_{\mathrm{e}}^{2}$.

The aim of the multilevel mixed analysis is to estimate the components of $\beta$ (fixed parameters of the model), $\mathbf{D}$ and $\mathbf{R}$ (variance components), together with the prediction of the EBLUP (empirical best linear unbiased predictor) for the random components associated with every plot, tree and plot $\times$ cork harvest (components of vector $\mathbf{b})$. Components were estimated using the restricted maximum likelihood method in SAS procedure MIXED [28]. Level of significance for variance components was analysed by means of the Wald test, while level of significance for fixed parameters was tested using Type III F-tests.

\subsubsection{Explanatory covariates identification}

In a first step, equation (1) was reduced to a basic model where only the intercept $\mu$ and random components $\mathrm{u}_{i}, \mathrm{v}_{i j}, \mathrm{w}_{i k}$ for the three correlation levels considered (tree, plot and plot $\times$ cork harvest) were taken into account. The basic multilevel mixed model expression for cork thickness was:

$$
\mathrm{cb}_{i j k}=\mu+\mathrm{u}_{i}+\mathrm{v}_{i j}+\mathrm{w}_{i k}+\mathrm{e}_{i j k}
$$

where $\mu$ is a fixed parameter defining the average cork thickness for the studied population; $\mathrm{u}_{i}, \mathrm{v}_{i j}, \mathrm{w}_{i k}$ and $\mathrm{e}_{i j k}$ as defined in equation (1). For this basic model, the predicted EBLUP's for the random components indicate systematic deviation from the population average cork 
thickness $(\mu)$ specific for the observations coming from the same plot, tree and cork harvest, respectively.

This pattern of systematic variability can be explained by including explanatory covariates (elements for vector $\mathrm{x}_{i j k}$ in Eq. (1)) acting at each of those specific levels. To identifiy those covariates which best explain deviations, first we calculated the correlation coefficient between EBLUP's and different attributes at stand, ecological and tree level. Only those variables showing significant correlation with the EBLUP's were evaluated for inclusion in model (6) as fixed effects. Criteria for the final inclusion of a covariate in the model were the level of significance for the parameters (fixed and random), reduction in the value of the components of the variance-covariance matrices, significant decrease for the statistic -2 times logarithm of the likelihood function (-2LL) and rate of explained variability. The variables evaluated were:

\section{- At stand level}

- Stand density: plot basal area under cork $\mathrm{G}_{\mathrm{ha}}\left(\mathrm{m}^{2} / \mathrm{ha}\right)$; mean squared diameter under cork $\mathrm{d}_{\mathrm{g}}(\mathrm{cm})$; number of trees per hectare $\mathrm{N}_{\text {ha }}$ (stems/ha); dominant diameter under cork $\mathrm{d}_{\text {dom }}(\mathrm{cm})$, average value for the $20 \%$ thickest trees within the plot.

- Other stand level covariates: canopy cover (\%); age (years); site index (m), calculated following Sánchez-González et al. [38].

\section{- At tree level}

- Tree-size: breast height diameter under cork $\mathrm{d}_{\mathrm{uc}}(\mathrm{cm})$; tree basal area under cork $\mathrm{g}_{\mathrm{uc}}\left(\mathrm{m}^{2}\right)$; crown width $\mathrm{cw}(\mathrm{m})$.

- Relative tree dimension: diameter under cork divided by mean squared diameter under cork $\mathrm{d}_{\mathrm{uc}} \cdot \mathrm{d}_{\mathrm{g}}^{-1}$; diameter under cork divided by maximum diameter under cork $\mathrm{d}_{\mathrm{uc}} \cdot \mathrm{d}_{\max }^{-1}$; diameter under cork divided by dominant diameter under cork $\mathrm{d}_{\mathrm{uc}} \cdot \mathrm{d}_{\mathrm{dom}}^{-1}$; basal area under cork divided by plot basal area under cork $\mathrm{g}_{\mathrm{uc}} \cdot \mathrm{G}^{-1}$; basal area under cork divided by maximum basal area under cork $\mathrm{g}_{\mathrm{uc}} \cdot \mathrm{g}_{\max }^{-1}$; basal area under cork divided by dominant basal area under cork $\mathrm{g}_{\mathrm{uc}} \cdot \mathrm{g}_{\mathrm{dom}}^{-1}$; the relation between the basal area of the ith tree and the total basal area divided by the number of trees per hectare apb.

- Competition indices: basal area of trees larger than i tree BAL.

\section{- Climatic attributes}

Altitude (m); annual rainfall (mm); spring rainfall (mm); autumn rainfall $(\mathrm{mm})$; mean annual temperature $\left({ }^{\circ} \mathrm{C}\right)$; evapotranspiration $(\mathrm{mm})$; surplus $(\mathrm{mm})$ sum of the difference between monthly rainfall and evapotranspiration in months that potential evapotranspiration is higher than monthly rainfall.

Climatic variables were obtained from the climatic models by Sánchez Palomares et al. [39], developed using data from the weather stations network of the National Institute of Meteorology and applying multiple linear regression methods with altitude, coordinates and basin of the subject point as explanatory variables.

Summary statistics for the analysed variables are shown in Table II.

\subsection{Calibration}

The main objective of the model is to detect the different sources of variability in cork thickness. Together with this, the fitted model can be used as a predictive tool for cork oak forest management.
Using the fixed effects part $\left(\mathrm{x}_{i j k} \beta\right)$ of a mixed model, it is possible to predict cork thickness in those locations where plot and tree explanatory variables included in the model are measured. In this case, we would obtain the fixed effects marginal prediction (i.e., value for $\left.\mathrm{E}\left[\mathrm{cb}_{i j k}\right]\right)$. Additionally, in a mixed model approach, it is possible to calibrate the model by predicting the random component specific for a new tree, plot or cork harvest, using a complementary sample of cork thickness measured in that unit $[27,46]$. Prediction of the random components is carried out using empirical best linear unbiased predictors (EBLUP) [40]:

$$
\hat{\mathbf{b}}=\hat{\mathbf{D}} \hat{\mathbf{Z}}^{\mathbf{T}}\left(\hat{\mathbf{R}}+\hat{\mathbf{Z}} \hat{\mathbf{D}} \hat{\mathbf{Z}}^{\mathbf{T}}\right)^{-1} \hat{\mathbf{e}}
$$

where $\hat{\mathbf{b}}$ is a vector including predicted random components for the new sampled units; $\hat{\mathbf{D}}, \hat{\mathbf{Z}}$ and $\hat{\mathbf{R}}$ are matrices including the predicted components for $\mathbf{D}, \mathbf{Z}$ and $\mathbf{R}$, defined for the additional sample; $\hat{\mathbf{e}}$ is a vector whose components are the values for the marginal unconditional residuals for the new sample (difference between the observed and the predicted cork thickness using the fixed effects marginal model). Inclusion of vector $\hat{\mathbf{b}}$ will allow us to obtain a random effects conditional prediction (i.e. $\mathrm{E}\left[\mathrm{cb}_{i j k} \mid \hat{\mathbf{b}}\right]$ ). To solve $\hat{\mathbf{b}}$ from equation (7), a SAS program was developed using IML language.

The accuracy of the calibration was evaluated using the data from the ten plots in the calibration data set comparing different alternatives of subsample size of cork thickness measurements in the plots $(1,2,4,6,8$ and 10 trees randomly selected). For each plot and subsample size, 100 random realizations were performed, each time including different trees in the calibration subsample. The statistics used in the comparison were: modelling efficiency (MEF) and root mean square error (RMSE) estimated as the mean value after 100 realizations.

$$
\begin{gathered}
\text { MEF }=1-\frac{\sum_{i=1}^{n}\left(y_{i}-\hat{y}_{i}\right)^{2}}{\sum_{i=1}^{n}\left(y_{i}-\bar{y}\right)^{2}} \\
\text { RMSE }=\sqrt{\frac{\sum\left(y_{i}-\hat{y}_{i}\right)^{2}}{n-1}}
\end{gathered}
$$

where $y_{i}, \hat{y}_{i}$ and $\bar{y}$ represents observed, predicted and average value for variable $\mathrm{y} ; \mathrm{n}$ represents the number of observations.

\section{RESULTS}

\subsection{Cork thickness modelling}

The results obtained after fitting the basic model in equation (6), considering simple variance structures for matrices $\mathbf{D}$ and $\mathbf{R}$, are included in the first column of Table III. The comparison of different spatial covariance structures for $\mathbf{D}$ revealed that the best results were obtained by considering a simple variance structure for matrix $\mathbf{D}_{\mathbf{u}}$ (no spatial correlation between plots) and a Gaussian spatial covariance structure for matrix $\mathbf{D}_{\mathbf{v}}$, indicating a pattern of spatial correlation between random tree components for the same plot (Tab. III, columns 2-4). All parameters, both for the basic and spatial models, were significant at the 0.01 level. Figure 2 shows the evolution of the pattern of spatial correlation between two trees as a function of distance, indicating that cork thickness shows 
Table II. Characterisation of variables evaluated as possible explanatory covariates.

\begin{tabular}{|c|c|c|c|c|c|c|}
\hline & Variable & Mean & Min & Max & STD & $\mathrm{CV}(\%)$ \\
\hline \multirow[t]{7}{*}{ Stand attributes } & $\mathrm{G}_{\mathrm{ha}}\left(\mathrm{m}^{2} \mathrm{ha}^{-1}\right)$ & 17.73 & 8.38 & 27.05 & 4.49 & 25.34 \\
\hline & $\mathrm{N}_{\text {ha }}\left(\right.$ stems ha $\left.{ }^{-1}\right)$ & 195.29 & 87.00 & 334.00 & 62.82 & 32.17 \\
\hline & $\mathrm{d}_{\mathrm{g}}(\mathrm{cm})$ & 35.21 & 24.33 & 56.86 & 6.35 & 18.03 \\
\hline & Site index (m) & 10.16 & 6.00 & 14.00 & 2.92 & 28.74 \\
\hline & Canopy cover (\%) & 15.86 & 8.60 & 26.62 & 4.67 & 29.44 \\
\hline & $\mathrm{d}_{\mathrm{dom}}(\mathrm{cm})$ & 42.01 & 29.48 & 79.29 & 8.29 & 19.72 \\
\hline & Age (years) & 98.30 & 53.00 & 177.00 & 31.61 & 32.16 \\
\hline \multirow[t]{7}{*}{ Climatic attributes } & Altitude (m) & 588 & 180.00 & 820.00 & 182.88 & 31.09 \\
\hline & Annual rainfall (mm) & 1257 & 1070.00 & 1391.00 & 81.54 & 6.49 \\
\hline & Spring rainfall $(\mathrm{mm})$ & 330 & 279.00 & 363.00 & 21.93 & 6.64 \\
\hline & Autumn rainfall $(\mathrm{mm})$ & 310 & 266.00 & 338.00 & 18.81 & 6.06 \\
\hline & Annual Temperature $\left({ }^{\circ} \mathrm{C}\right)$ & 16.00 & 15.00 & 18.00 & 0.67 & 4.13 \\
\hline & Evapotranpiration (mm) & 826.00 & 792.00 & 879.00 & 25.39 & 3.07 \\
\hline & Surplus (mm) & 884.00 & 688.00 & 1013.00 & 84.49 & 9.56 \\
\hline \multirow[t]{11}{*}{ Tree attributes } & $\mathrm{d}_{\mathrm{uc}}(\mathrm{cm})$ & 31.12 & 14.01 & 61.43 & 7.13 & 22.92 \\
\hline & $\mathrm{g}_{\mathrm{uc}}\left(\mathrm{m}^{2}\right)$ & 0.08 & 0.02 & 0.30 & 0.04 & 47.36 \\
\hline & Crown diameter $(\mathrm{m})$ & 3.05 & 0.50 & 7.10 & 0.93 & 30.66 \\
\hline & $\mathrm{d}_{\mathrm{uc}} \cdot \mathrm{d}_{\mathrm{g}}^{-1}$ & 0.93 & 0.42 & 1.55 & 0.18 & 19.37 \\
\hline & $\mathrm{d}_{\mathrm{uc}} \cdot \mathrm{d}_{\max }^{-1}$ & 0.89 & 0.17 & 2.41 & 0.34 & 38.51 \\
\hline & $\mathrm{d}_{\mathrm{uc}} \cdot \mathrm{d}_{\mathrm{dom}}^{-1}$ & 0.59 & 0.14 & 1.00 & 0.20 & 34.18 \\
\hline & $\mathrm{guc}_{\mathrm{uc}} \cdot \mathrm{G}^{-1}$ & 0.39 & 0.02 & 1.00 & 0.24 & 60.79 \\
\hline & $\mathrm{g}_{\mathrm{uc}} \cdot \mathrm{g}_{\max }^{-1}$ & 0.80 & 0.41 & 1.34 & 0.15 & 18.45 \\
\hline & $\mathrm{g}_{\mathrm{uc}} \cdot \mathrm{g}_{\mathrm{dom}}^{-1}$ & 0.67 & 0.17 & 1.79 & 0.24 & 36.26 \\
\hline & apb & 45.14 & 6.64 & 133.34 & 22.63 & 50.13 \\
\hline & $\operatorname{BAL}\left(\mathrm{m}^{2} / \mathrm{ha}\right)$ & 11.57 & 0.00 & 26.82 & 5.79 & 50.09 \\
\hline
\end{tabular}

Min: Minimum; Max: maximum; STD: standard deviation; CV: coefficient of variation; $\mathrm{G}_{\text {ha }}$ : plot basal area under cork; $\mathrm{N}_{\text {ha }}$ : number of trees per ha; $\mathrm{d}_{\mathrm{g}}$ : mean square diameter under cork; $\mathrm{d}_{\mathrm{dom}}$ : dominant diameter under cork; $\mathrm{d}_{\mathrm{uc}}$ : diameter at breast height under cork; guc : tree basal area under cork; $\mathrm{d}_{\max }$ : maximum diameter under cork of the plot; G: plot basal area under cork; $\mathrm{g}_{\max }$ : maximum basal area under cork; $\mathrm{g}_{\text {dom }}$ : dominant basal area under cork; apb: area proportional to tree basal area; BAL: mean basal area of the trees larger than $i$ th tree where $\mathrm{d}_{\mathrm{j}}>\mathrm{d}_{\mathrm{i}}$.

Table III. Comparison of fitting statistics and estimated variance components of the basic and spatial models.

\begin{tabular}{|c|c|c|c|c|}
\hline & Basic linear mixed model & Exponential spatial structure model & Gaussian spatial structure model & Power spatial structure model \\
\hline$\mu$ & 25.7731 & 25.7724 & 25.7621 & 25.7724 \\
\hline$\rho$ & & 1.6805 & 2.0107 & 0.5516 \\
\hline$\sigma_{\mathrm{u}}^{2}($ tree $)$ & 19.4756 & 19.5968 & 19.4642 & 19.5970 \\
\hline$\sigma_{\mathrm{v}}^{2}(\mathrm{plot})$ & 5.9588 & 5.6889 & 5.8933 & 5.6896 \\
\hline $\begin{array}{l}\sigma_{\mathrm{w}}^{2}(\text { plot } \times \\
\text { cork harvest })\end{array}$ & 3.9412 & 3.9429 & 3.6430 & 3.9449 \\
\hline$\sigma_{\mathrm{e}}^{2}($ error $)$ & 7.5337 & 7.5321 & 7.5235 & 7.5319 \\
\hline$-2 \mathrm{LL}$ & 9332.6 & 9329.9 & 9323.6 & 9324.9 \\
\hline
\end{tabular}

$\mu$ : Fixed parameter defining the average cork thickness for the studied population; $\rho$ : correlation parameter; $\sigma^{2}$ : variance terms; $-2 \mathrm{LL}:-2$ times logarithmic of likelihood. 


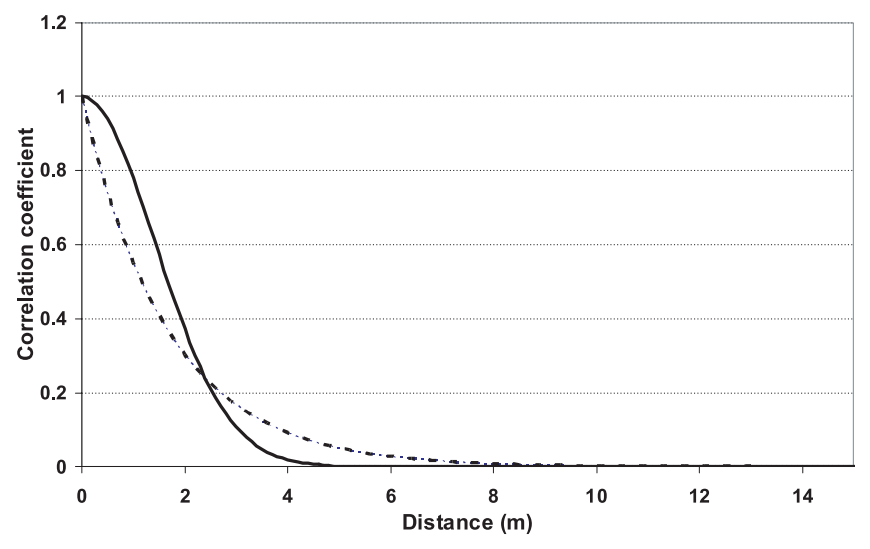

Figure 2. Spatial correlogram for tree random effect, comparing Gaussian (solid line) with power and exponential (dashed lines) covariance structures (overlapped).

spatial correlation, at tree level, up to a distance of $5 \mathrm{~m}$. The spatial correlograms corresponding to the power and exponential covariance structures are overlapped. Under the proposed Gaussian spatial structure, the components of the variance matrix for the observations $\mathbf{V}$ would be:

- Variance for a single observation:

$$
\sigma_{\mathrm{u}}^{2}+\sigma_{\mathrm{v}}^{2}+\sigma_{\mathrm{w}}^{2}+\sigma_{\mathrm{e}}^{2}
$$

- Covariance between two observations taken in the same inventory, from two trees in the same plot separated a distance $\mathrm{d}_{12}$ :

$$
\sigma_{\mathrm{u}}^{2}+\sigma_{\mathrm{w}}^{2}+\sigma_{\mathrm{v}}^{2}\left[\exp \left(\frac{-\left(\mathrm{d}_{12}^{2}\right)}{\rho^{2}}\right)\right]
$$

- Covariance between two observations taken in different inventories from the same tree:

$$
\sigma_{u}^{2}+\sigma_{v}^{2}
$$

- Covariance between two observations taken in different inventories from different trees in the same plot, separated a distance $\mathrm{d}_{12}$ :

$$
\sigma_{u}^{2}+\sigma_{v}^{2}\left[\exp \left(\frac{-\left(d_{12}^{2}\right)}{\rho^{2}}\right)\right]
$$

The highest level of variability $(53 \%)$ is associated with tree effects, while the between cork harvest random effect for plots accounted for the lowest level (10\%) of the total non explained variability. Plot level effects explain $16 \%$ of the variability while the remaining $21 \%$ is associated with residual (tree $\times$ cork harvest) effects.

The mean variance value obtained for the $\mathrm{e}_{i j k}$ conditional residual terms after fitting the basic model was computed for each different class of explanatory variables and plotted against them. No pattern of non-constant variance in the residuals (heteroscedasticity) was detected, indicating that the selected simple structure for matrix $\mathbf{R}$ is adequate. The plot of $\mathrm{e}_{i j k}$ against predicted values (not shown) displays an increasing trend, indicating the need to identify explanatory covariates which are dealt with in the next section.
Table IV. Correlation coefficients of plot random effect and stand and ecological covariates.

\begin{tabular}{lcc}
\hline Covariates & Pearson's coefficient & $P$ value \\
\hline Stand attributes & -0.1383 & \\
\hline Basal area & 0.0770 & 0.4402 \\
Density & -0.1211 & 0.6504 \\
Mean square diameter & -0.2692 & 0.4753 \\
Site index & -0.1823 & 0.1071 \\
Canopy cover & 0.0955 & 0.2777 \\
Dominant diameter & 0.2651 & 0.9553 \\
Age & & 0.1128 \\
\hline Ecological attributes & 0.1403 & \\
\hline Altitude & -0.1620 & 0.9343 \\
Annual rainfall & -0.1382 & 0.3379 \\
Spring rainfall & -0.1381 & 0.4146 \\
Autumn rainfall & -0.0099 & 0.415 \\
Annual temperature & -0.0217 & 0.9536 \\
Evapotranspiration & -0.1450 & 0.8986 \\
Surplus & & 0.3918 \\
\hline
\end{tabular}

To test the behaviour in $\sigma_{\mathrm{v}}^{2}$ the variance for EBLUP's $\mathrm{v}_{i j}$ was computed per categorical class for the different stand attributes considered in Table II. We detected a pattern (not shown) of reduction in variance associated with increasing classes of canopy cover, basal area and mean squared diameter and decreasing classes of stand density. This indicates that within plot tree variability in cork thickness is larger in younger phases of stand development, tending towards homogeneity in mature states. After evaluating various alternatives, the following model for tree level variance depending on mean squared diameter was proposed:

$$
\sigma_{\mathrm{v}}^{2}=0.0566 \mathrm{~d}_{\mathrm{g}}^{2}-4.8556 \mathrm{~d}_{\mathrm{g}}+114.04
$$

\subsection{Identification of explanatory covariates}

The EBLUP's for random parameters $\mathrm{u}_{i}, \mathrm{v}_{i j}$ and $\mathrm{w}_{i k}$ were expanded over different covariates. Tables IV and V show the correlation coefficients between random components and possible explanatory covariates as well as their transformations. None of the stand or climatic attributes evaluated were identified as significantly correlated with random plot components. In order to evaluate possible trends, charts of the predicted EBLUP's $u_{i}$ for random plot effect against the stand and ecological variables were also assessed. From this graphical analysis, a slight positive trend with age was detected $(r=0.26$, $p=0.10$; Fig. 3), indicating that older stands tend to have thicker cork than younger ones. No significant relation was identified between plot-level EBLUP's $\mathrm{u}_{\mathrm{i}}$ and climatic variables (Fig. 4). Regarding tree attributes, initial tree diameter and section area were significantly correlated with predicted EBLUP's for $\mathrm{v}_{i j}$ at the 0.05 level, while several competition 
Table V. Correlation coefficients of tree random effect and tree covariates.

\begin{tabular}{lcc}
\hline Covariates & Pearson's coefficient & $P$ value \\
\hline $\mathrm{d}_{\mathrm{uc}}$ & 0.0737 & 0.0377 \\
$\mathrm{~g}_{\mathrm{uc}}$ & 0.0703 & 0.0362 \\
$\mathrm{cw}$ & 0.0642 & 0.0782 \\
$\mathrm{~d}_{\mathrm{uc}} \cdot \mathrm{d}_{\mathrm{g}}^{-1}$ & 0.1038 & 0.0034 \\
$\mathrm{~d}_{\mathrm{uc}} \cdot \mathrm{d}_{\max }^{-1}$ & 0.0633 & 0.0747 \\
$\mathrm{~d}_{\mathrm{uc}} \cdot \mathrm{d}_{\mathrm{dom}}^{-1}$ & 0.0954 & 0.0071 \\
$\mathrm{~g}_{\mathrm{uc}} \cdot \mathrm{G}^{-1}$ & 0.1089 & 0.0021 \\
$\mathrm{~g}_{\mathrm{uc}} \cdot \mathrm{g}_{\max }^{-1}$ & 0.0606 & 0.0875 \\
$\mathrm{~g}_{\mathrm{uc}} \cdot \mathrm{g}_{\mathrm{dom}}^{-1}$ & 0.0172 & 0.0041 \\
$\mathrm{apb}$ & 0.0737 & 0.0371 \\
$\mathrm{BAL}$ & -0.0891 & 0.0129 \\
\hline
\end{tabular}

$\mathrm{d}_{\mathrm{uc}}$ : Diameter at breast height under cork; $\mathrm{g}_{\mathrm{uc}}$ : tree basal area under cork; $\mathrm{cw}$ : crown width; $\mathrm{d}_{\mathrm{g}}$ : mean square diameter under cork; $\mathrm{d}_{\max }$ : plot maximum diameter under cork; $\mathrm{d}_{\mathrm{dom}}$ : dominant diameter under cork; $\mathrm{G}$ : plot basal area under cork; $\mathrm{g}_{\max }$ : maximum basal area under cork; $\mathrm{g}_{\mathrm{dom}}$ : dominant basal area under cork; apb: area proportional to tree basal area; BAL: mean basal area of the trees larger than $i$ th tree where $\mathrm{d}_{j}>\mathrm{d}_{i}$.

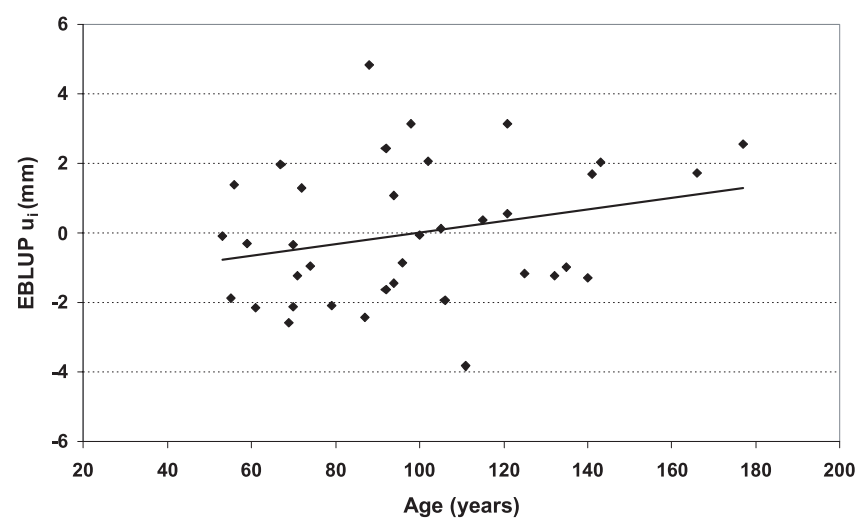

Figure 3. Random plot effect in relation to plot age.

indices $\left(\mathrm{d}_{\mathrm{uc}} \cdot \mathrm{d}_{\mathrm{g}}^{-1}, \mathrm{~d}_{\mathrm{uc}} \cdot \mathrm{d}_{\mathrm{dom}}^{-1}, \mathrm{~g}_{\mathrm{uc}} \cdot \mathrm{G}^{-1}, \mathrm{~g}_{\mathrm{uc}} \cdot \mathrm{g}_{\mathrm{dom}}^{-1}, \mathrm{apb}\right)$ were significantly correlated at 0.01 level.

Only those covariates significantly correlated with random components were evaluated for inclusion in the model in a linear form. Several models including different subsets of explanatory variables were evaluated in terms of -2 log likelihood ratio tests. Although the inclusion of tree level attributes lead to significant likelihood improvements, it was finally decided that none of the models which considered explanatory covariates would be used because, at best, the percentage of explained variability was less than $2 \%$.

\subsection{Calibration}

As none of the explanatory covariates were identified as significant and useful in explaining cork thickness variability, calibration was proposed as an alternative approach to obtain estimates for cork thickness. Figure 5 shows the results of the calibration carried out in the ten plots of the calibration data set, comparing different sizes of sample for calibrating cork thickness. These additional measurements were used to predict both random plot and plot $\times$ cork harvest components, which were then added to the model.

Calibration tends to be more efficient as subsample size increases, although only small differences exist between a fourtree sample and a larger one. Calibration using four trees lead to modelling efficiencies (at plot level) between 0.15 and 0.60 (except for plot 57, not shown in the figure, where calibration does not improve the use of the average population model). The root mean square error obtained through a four-tree calibration ranges from 4.75 to $8.33 \mathrm{~mm}$ (except for plot 53, where RMSE is over $10 \mathrm{~mm}$ ).

\section{Case study: application of the calibration approach to estimate cork production}

In the study area, cork weight at tree level has traditionally been estimated using the model proposed by Montero [29], where cork weight is given by the following expression:

$$
\mathrm{w}=13.44 \cdot \mathrm{sh} \cdot \mathrm{cbh}
$$

Where w is cork weight just after debarking $(\mathrm{kg})$, sh is stripped height $(\mathrm{m})$ and cbh is circumference at breast height under bark (m).

In this study we propose the use of the developed cork thickness model to predict cork weight, using the following expression:

$$
\mathrm{w}=\mathrm{cb} \cdot \mathrm{sh} \cdot \mathrm{cbh} \cdot \operatorname{cork} \text { density }
$$

Where w, sh and cbh are as previously stated; $\mathrm{cb}$ is predicted cork thickness (in mm) and cork density is referred to as the relation between cork weight and volume, which has been calculated for the area at $420 \mathrm{~kg} / \mathrm{m}^{3}$.

Data from the ten calibration plots were used to estimate cork weight using both expressions (11) and (12). Table VI shows the relative error (13) in estimating cork weight attained using the Montero [29] approach (11), or using expression (12), calibrating cork thickness with different subsample sizes.

$$
\text { Relative error }(\%)=100 \frac{(\hat{y}-y)}{y}
$$

Where y and y represents estimated (from Eq. (11) or Eq. (12)) and observed plot cork weight respectively. Using the present model, calibration using cork thickness data from only four additional trees, leads to a relative error under $10 \%$ in eight of the ten plots analysed, giving slightly better results than the previous model, except for plots 53-55.

The proposed calibration approach also allows the estimation of cork weight from trees with a mean cork thickness greater than $27 \mathrm{~mm}$, which is considered the limit value for the stopper industry. This was done by estimating cork weight 

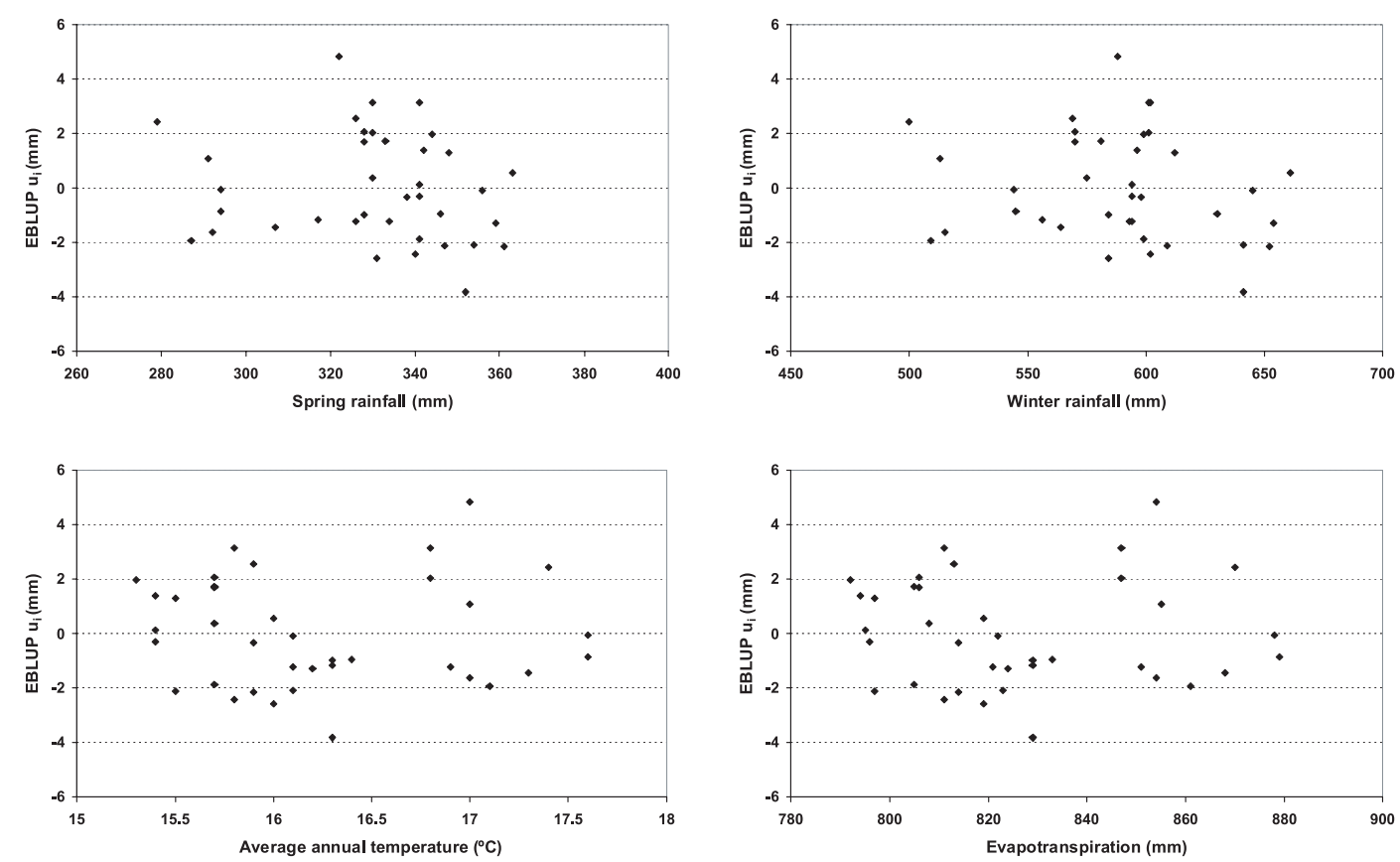

Figure 4. Random plot effect in relation to main climatic attributes.

at tree level which involved, along with the predicted random plot and plot $\times$ cork harvest components, a stochastic tree level component defined by a random realization from a normal distribution with mean zero and common plot variance given by equation (10). For each plot we have computed 100 Monte Carlo simulations, randomly assigning a stochastic component for each tree in each simulation, and computing cork production destined for the stopper industry as the average value for those 100 realizations. Figure 6 shows the relation between observed and predicted cork weight per plot for the stopper industry. The relative errors obtained in predicting cork for the stopper industry ranges from 2-15\% (except for plot 21, where the model predicted $145 \mathrm{~kg}$, while the observed cork weight for the stopper industry was only $48 \mathrm{~kg}$ ).

\section{DISCUSSION}

\subsection{Identification of variables influencing cork thickness}

In this study, we evaluate the influence of different variables on cork thickness in cork oak forests. For this purpose, first we fitted a multilevel linear mixed model for predicting average cork thickness, including random parameters acting at plot, tree, plot $\times$ cork harvest and residual within-tree levels, and considering spatial covariance structure between trees within the same plot. In a second step the explanatory covariates were identified by studying their possible correlation with random effects. The mixed model approach was proposed by Vázquez [44] for modelling cork weight prediction and for modelling the yield of other non-timber products, such as stone pine cones [3] or cowberry production [23].

The largest part of non-explained variability (53\%) is associated with tree effect. Tree size, given by breast height diameter or section, and relative tree dimension indices, have a positive correlation with random tree effect. This positive correlation with size and competition indexes, might be related to the fact that in Mediterranean ecosystems water use (availability and temporal variation) is more efficient in larger individuals [24, 26]. Vázquez [44] obtained a similar result when modelling cork weight prediction.

The results obtained indicate that unobservable tree factors, which remain constant from one cork harvest period to the next, exert some influence over cork thickness. These factors can be related to microsite or genetics. It is known that cork quality variability is high even under identical site conditions $[7,14,18,45]$, so results suggest a close relationship between cork thickness and genetic aspects. The small correlation distance $(<5 \mathrm{~m})$ detected among tree random components from the same plot may confirm the strong dependence of cork thickness on genetic factors, as trees within a short distance of each other would more than likely belong to the same parent tree or stump sprout. The predicted EBLUP's for the random tree component, specific to each tree, might be considered indices for selecting trees with the highest cork production once plot or period effects have been accounted for, indicating the utility of mixed models in genetic improvement programs [22].

Sixteen percent of the non-explained variability is related to between-plot variability. When representing random plot effect vs. age (Fig. 3) a slight trend can be identified as cork thickness is greater in older stands. A similar trend was detected by Costa et al. [8] in their analysis of cork growth variability, in which they reported a slight trend of increasing cork increments with tree diameter. In the other hand, Vieira [45] 

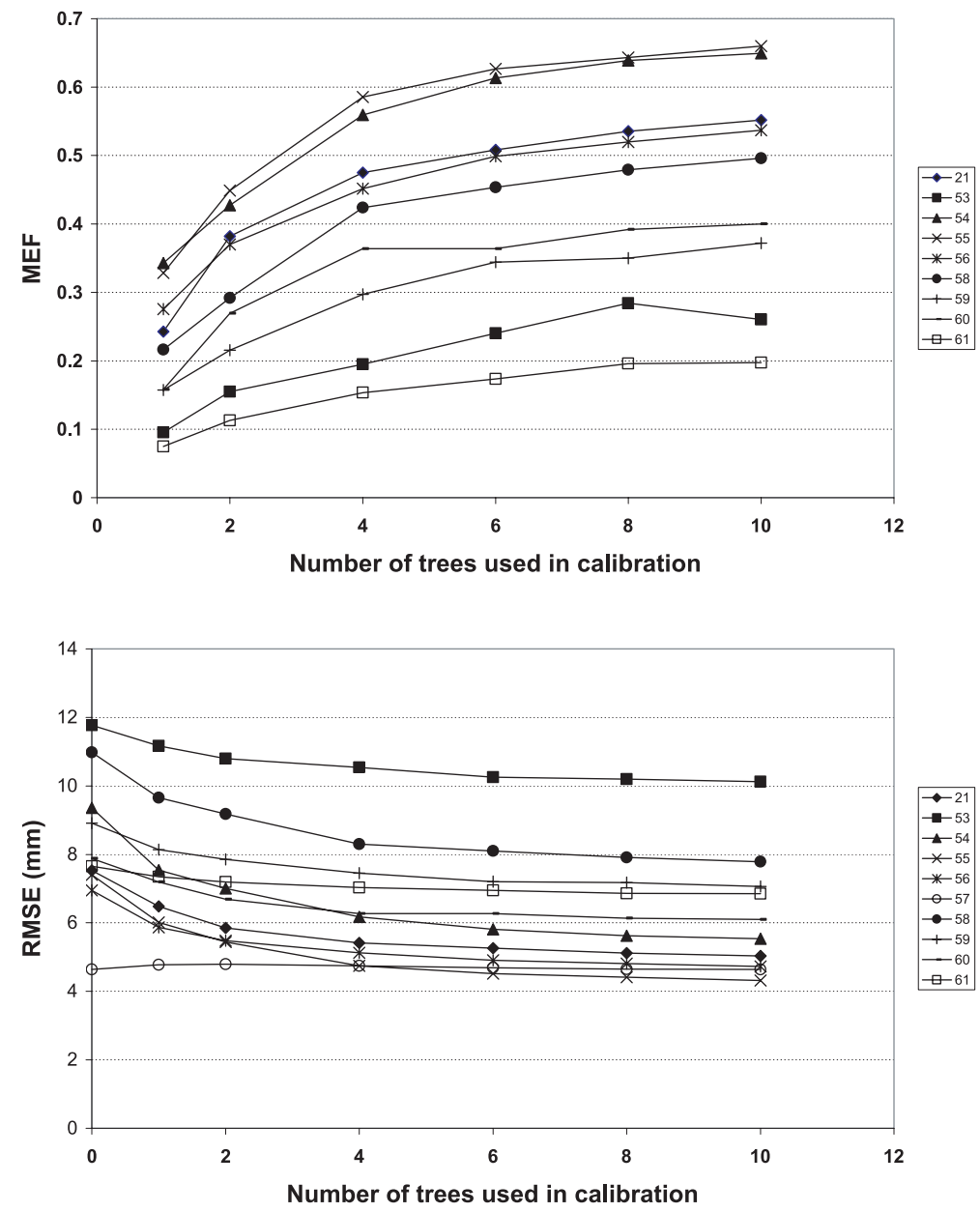

Figure 5. Modelling efficiency (MEF) and root mean square error (RMSE) for cork thickness estimation in calibration data set (10 plots), as a function of the number of trees used in calibration.

Table VI. Relative error in estimating cork weight using the model by Montero (1987) and the model proposed in the present work comparing different subsample size for calibration.

\begin{tabular}{|c|c|c|c|c|c|c|c|c|c|}
\hline \multirow{2}{*}{ PLOT } & \multirow{2}{*}{$N$} & \multirow{2}{*}{ w } & \multirow{2}{*}{ Montero (1987) } & \multicolumn{6}{|c|}{ Calibration sample size } \\
\hline & & & & 1 tree & 2 trees & 4 tress & 6 trees & 8 trees & 10 trees \\
\hline$\overline{21}$ & 39 & 540 & $76.57 \%$ & $35.35 \%$ & $29.36 \%$ & $23.77 \%$ & $22.05 \%$ & $19.69 \%$ & $18.43 \%$ \\
\hline 53 & 19 & 633 & $-2.76 \%$ & $-15.14 \%$ & $-11.63 \%$ & $-9.31 \%$ & $-6.20 \%$ & $-5.35 \%$ & $-5.06 \%$ \\
\hline 54 & 13 & 450 & $-4.52 \%$ & $-15.15 \%$ & $-12.58 \%$ & $-8.14 \%$ & $-5.77 \%$ & $-4.29 \%$ & $-3.71 \%$ \\
\hline 55 & 14 & 354 & $-5.66 \%$ & $-17.80 \%$ & $-15.19 \%$ & $-11.34 \%$ & $-9.69 \%$ & $-8.59 \%$ & $-7.99 \%$ \\
\hline 56 & 18 & 642 & $7.33 \%$ & $-6.92 \%$ & $-4.40 \%$ & $-1.79 \%$ & $0.21 \%$ & $1.27 \%$ & $2.09 \%$ \\
\hline 57 & 12 & 422 & $17.87 \%$ & $-3.00 \%$ & $-2.13 \%$ & $-2.08 \%$ & $-2.42 \%$ & $-1.72 \%$ & $-1.39 \%$ \\
\hline 58 & 33 & 821 & $4.41 \%$ & $-7.87 \%$ & $-4.93 \%$ & $1.14 \%$ & $3.36 \%$ & $5.54 \%$ & $6.73 \%$ \\
\hline 59 & 26 & 532 & $12.25 \%$ & $-2.62 \%$ & $-0.66 \%$ & $4.01 \%$ & $6.89 \%$ & $6.97 \%$ & $9.02 \%$ \\
\hline 60 & 40 & 683 & $7.89 \%$ & $-7.77 \%$ & $-3.55 \%$ & $0.48 \%$ & $0.75 \%$ & $1.93 \%$ & $2.83 \%$ \\
\hline 61 & 40 & 623 & $18.70 \%$ & $1.25 \%$ & $2.92 \%$ & $5.89 \%$ & $8.05 \%$ & $8.20 \%$ & $8.22 \%$ \\
\hline All plots & 254 & 5698 & $13.16 \%$ & $-3.81 \%$ & $-1.98 \%$ & $0.76 \%$ & $2.28 \%$ & $2.99 \%$ & $3.58 \%$ \\
\hline
\end{tabular}

w: Cork weight $(\mathrm{kg} / \mathrm{plot}) ; \mathrm{N}$ : number of trees per plot. 


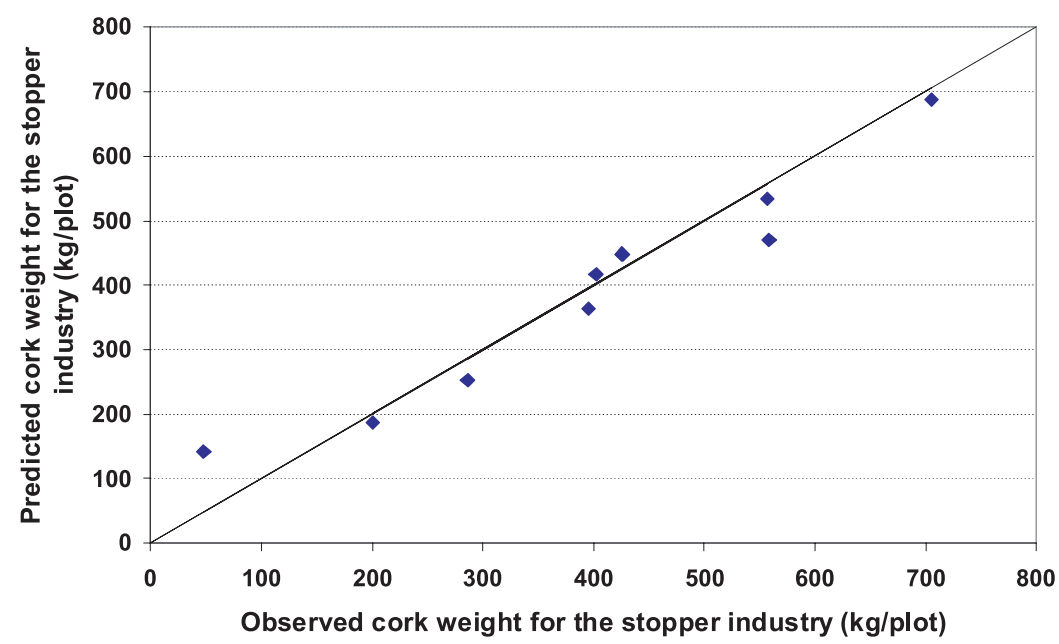

Figure 6. Observed versus predicted (using calibration from four trees per plot) cork weight for stopper industry in calibration plots.

and Figueroa [15] detected through a graphical assessment, a significant decrease in cork thickness after tenth debarking. Plots we analysed were mainly between 65 and 135 years old, so most of the plots have still not reached the 10th debarking rotation. This could explain the fact that no significant decreasing correlation between plot age and random plot effect has been detected in our work.

We found no correlation between cork thickness and stand density attributes. This result is in accordance with Cañellas et al. [5] and Torres et al. [43], who reported that density does not influence cork thickness, at least for the range of density values in the data set used for those studies.

Cork thickness is related to site conditions, as stated by Ferreira et al. [14], Corona et al. [7] and Montero and Cañellas [32]. Despite this, the site index proposed by Sánchez-González et al. [38] is not significantly correlated with random plot effects. Traditional site indices, using dominant height as an indicator of timber productivity, have shown their validity in predicting growth and timber yield in Mediterranean species $[1,3,33]$, but do not work so well when used to estimate other productions, such as pine nuts, cork or resin, which in Mediterranean ecosystems could constitute more than $50 \%$ of the total annual biomass produced [2]. More exhaustive site indices which include ecological factors are needed for the species. Therefore, this line of research should be considered a priority for future studies.

This lack of relationship between cork thickness and density or site index is directly related to the high variability found in trees growing in the same neighbourhood and confirms the result that most of the cork thickness variability is associated with tree effect. In that sense, it would be important to find an indicator which permits the evaluation of cork thickness at tree level prior to the establishment of the stand or in very young plantations. For this purpose, isotopic fingerprints of soils and vegetations have been used to find possible relationships between stable isotope measurements at natural abundance levels and the quality of the standing tree mass in Pinus pinaster and Pinus sylvestris plantations [13], as well as in multiple regression models to predict the site index variation in Pinus radiata stands [19]. In future research, it would be interesting to try this technique in order to evaluate future cork thickness at tree level or to use soil isotopic signatures in process models to predict cork thickness.

Previous studies concerning the influence of climate on cork growth have concluded that the main climatic factors are: summer drought [6], summer temperatures [6], spring precipitation [37] and autumn-winter precipitations [6, 8, 9, 37]. However, in the present study, climatic attributes were not found to be correlated with cork thickness. The result for the precipitation parameters can be explained by the fact that in the study area, the annual precipitation varies between 1000 and $1400 \mathrm{~mm}$ (depending on altitude), whereas in the aforementioned studies, the areas under analysis receive a mean annual precipitation of around $600 \mathrm{~mm}$. We must also take into account that those studies related annual cork increments to annual or monthly values of the climatic factors whilst our study used mean values for climatic parameters at each debarking period. Possible effects may have been lost through using mean values.

The between-cork-harvest variability at plot level accounts for $10 \%$ of total variability, indicating differences between growth periods, at least at plot level, almost certainly related to long-term climatic effects like drought, such as that suffered in Spain between 1993 and 1995. The between-cork-harvest residual variance at tree level accounts for $21 \%$ of the total non-explained variability. This could be related to abnormal variations in debarking intensity, either because of prior debarking damages or as a result of years of conditions that make cork extraction more difficult, such as hot windy days or serious attacks of Lymantria dispar (among others) [31].

\subsection{Calibration}

None of the models which considered explanatory covariates were used because, at best the percentage of explained variability, it was less than $2 \%$. Nevertheless, by identifying 
the different sources of variability it is possible to calibrate the model for new locations using a small amount of cork thickness data (obtained using a cork calliper) from each plot.

When additional measurements from four trees per plot were used for calibration, the modelling efficiency was over $30 \%$ in 7 of the 10 calibration plots analysed, indicating a significant improvement over using an average cork thickness value for the entire region. In any case, considering that plot and plot $\times$ cork harvest levels jointly explain $26 \%$ of nonexplained variability in the fitting data set, it is unlikely that the results obtained would be improved by including a larger number of trees in the calibration subsample. With respect to RMSE, calibration reduces it by more than $2 \mathrm{~mm}$ in 8 of the calibration plots when compared to the original deviation from the population average. These values are deemed as acceptable, taking into account the large within-plot variability in cork thickness detected. In general, calibration at plot level tends to be more effective in those plots where average cork thickness is largely deviated with respect to the average cork thickness for the population.

The proposed four trees calibration approach could be useful in predicting cork weight, obtaining better predictions than Montero's model [29]. The main advantage of the proposed approach compared to previously developed models is that together with cork weight, it is possible to estimate cork thickness, which is the variable that most affects cork value. By using Monte Carlo simulations to assign random components for each tree within the plot it is possible to use the calibration approach to classify total cork production at plot level. For example, trees with a mean cork thickness of less than $27 \mathrm{~mm}$ would not be useful for the stopper industry.

\section{CONCLUSIONS}

The model developed help us to improve our knowledge of cork thickness variability, identifying sources of non explained variability and allowing us to identify further factors (at tree, stand or period level), which need to be analysed for future improvements to the model.

The model confirms the slight relationship between silviculture and cork thickness, and the probable dependence of this variable on unobservable site factors not related with average climatic conditions.

Large variability in cork thickness is associated with unobservable tree attributes, probably to do with genetics or microsite rather than social status.

Prediction of random components using a small sample of additional measurements converts the proposed model into a useful tool for predicting cork thickness and weight, allowing us to classify the cork with respect to its final use in the cork industry. In that sense, calibration measuring cork thickness in four trees per plot seems an interesting and low cost approach when compared to previously developed models.

Acknowledgements: The research was partially supported by a grant to the corresponding author from the CIFOR-INIA. The authors wish to thank E. Torres for providing plot and tree coordinates.
We also wish to thank the two anonymous reviewers for their helpful comments and suggestions.

\section{REFERENCES}

[1] Bravo-Oviedo A., del Río M., Montero G., Site index curves and growth model for Mediterranean maritime pine (Pinus pinaster Ait.) in Spain, For. Ecol. Manage. 201 (2004) 187-197.

[2] Cabanettes A., Rapp M., Biomasse, minéralomasse et productivité d'un écosystème à pins pignons (Pinus pinea L.) du littoral méditerranéen. III. Croissance, Acta Oecol. Plant. 2 (1981) 121-136.

[3] Calama R., Modelo interregional de selvicultura para Pinus pinea L. Aproximación mediante funciones con componentes aleatorio, Ph.D. thesis, Universidad Politécnica de Madrid, 2004.

[4] Calama R., Montero G., Multilevel linear mixed model for tree diameter increment in stone pine (Pinus pinea): a calibrating approach, Silva Fenn. 39 (2005) 37-54.

[5] Cañellas I., Bachiller A., Montero G., Influencia de la densidad de la masa en la producción de corcho en alcornocales adehesados de Extremadura, Actas del Congreso de Ordenación y Gestión Sostenible de Montes, Santiago de Compostela, 4-9 de Octubre de 1999, Ponencias y Resúmenes de Comunicaciones, Tomo I, 2000, pp. 449-456.

[6] Caritat A., Gurierrez E., Molinas M., Influence of weather on corkring width, Tree physiol. 20 (2000), 893-900.

[7] Corona P., Dettori S., Filigheddu M.R., Maetzke F., Scotti R., Site quality evaluation by classification tree: an application to cork quality in Sardinia, Eur. J. For. Res. 124 (2005) 37-46.

[8] Costa A., Pereira H., Oliveira A., Variability of radial growth in cork oak mature trees under cork production, For. Ecol. Manage. 175 (2003) 239-246.

[9] Costa A., Pereira H., Oliveira A., Influence of climate on the seasonality of radial growth of cork oak during a cork production cycle, Ann. For. Sci. 59 (2002) 429-437.

[10] De Benito Ontañón N., Cork oak stands in Cortes de la Frontera, Proceedings of the IUFRO Meeting Mediterranean Silviculture with emphasis in Quercus suber, Pinus pinea and Eucalyptus sp., 2000.

[11] Falcao A.O., Borges J.G., Designing decision support tools for Mediterranean forest ecosystems management: case study, Ann. For. Sci. 62 (2005) 751-760.

[12] FAO, World Reference Base for Soil Resources, World Soil Resources Reports, 84, Rome, 1998.

[13] Fernández I., González-Prieto A.J., Cabaneiro A., C-isotopic fingerprints of Pinus pinaster Ait. and Pinus sylvestris L. wood related to the quality of standing tree mass in forests from NW Spain, Rapid Commun. Mass Spectrom. 19 (2005) 3199-3206.

[14] Ferreira A., Lopes F., Pereira H., Caractérisation de la croissance et de la qualité du liège dans une région de production, Ann. For. Sci. 57 (2000) 187-193.

[15] Figueroa P., Alcornocales e Industria Corchera, Conferencia sobre alcornocales, E.T.S.I. Montes, Madrid, 1957.

[16] Fox J.C., Ades P.K., Bi H., Stochastic structure and individual-tree growth models, For. Ecol. Manage.154 (2001) 261-276.

[17] Goldstein H., Multilevel Statistical Models, 2nd. ed., Arnold Publishers, London, 1995.

[18] González Adrados J.R., González Hernández R., Calvo Haro R., La predicción del calibre de corcho al final del turno y su aplicación al muestreo de la producción, Investig. Agrar., Sist. Recur. For. 9 (2000) 363-373.

[19] González-Prieto S.F., Villar M.C. Soil organic N dynamics and stand quality in Pinus radiata pinewoods of the temperate humid region, Soil Biol. Biochem. 35 (2003) 1395-1404. 
[20] Gregoire T.G., Generalized error structure for forestry yield models, For. Sci. 33 (1987) 423-444.

[21] Gourlay I.D., Pereira H., The effect of bark stripping on wood production in cork-oak (Quercus suber L.) and problems of growth ring definition, in: Pereira H. (Ed.), Proceedings of the European Conference on Cork Oak and Cork, Centro de Estudos Florestais, Lisboa, 1998, pp. 99-107.

[22] Henderson C.R., Kempthorne O., Searle S.R., Von Krosing C.N., Estimation of environmental and genetic trends from records subject to culling, Biometrics 15 (1959) 192-218.

[23] Ihalainen M., Salo K., Pukkala T., Empirical prediction models for Vaccinium myrtillus and V. vitis-idaea berry yields in North Karelia, Finland, Silva Fenn. 37 (2003) 95-108.

[24] Koechlin B., Rambal S., Debussche M., Rôle des arbres, pionniers sur la teneur en eau du sol en surface de friches de la región méditerranéenne, Acta Oecol. 7 (1986) 177-190.

[25] Kyrikiadis P.C., Journel A.G., Geostatistical space-time models: a review, Math. Geol. 31 (1999) 651-684.

[26] Landsac A.R., Zaballos J.P., Martin A., Seasonal water potential changes and proline accumulation in Mediterranean shrubland species, Vegetatio, 113 (1994) 141-154.

[27] Lappi J., Bailey R.L., A height prediction model with random stands and tree parameters: an alternative to traditional site index methods, For. Sci. 34 (1988) 907-927.

[28] Littell R.C., Milliken A.G., Stroup W.W., Wolfinger R.D., SAS system for mixed models, SAS Institute Inc., Cary, NC, 1996, 633 p.

[29] Montero G., Modelos para cuantificar la producción de corcho en alcornocales (Quercus suber L.) en función de la calidad de estación y los tratamientos selvícolas, Ph.D. thesis, INIA, Madrid, 1987, $277 \mathrm{p}$.

[30] Montero G., Vallejo R., Variación del calibre de corcho medido a distintas alturas, Investig. Agrar., Sist. Recur. For. 2 (1992) 181-188.

[31] Montero G., Cañellas I., Manual de forestación del alcornoque (Quercus suber L.), MAPA-INIA, 1999.

[32] Montero G., Cañellas I., Selvicultura de los alcornocales en España, Silva Lusitana 11 (2003) 1-19.
[33] Montero G., Cañellas I., Ruiz-Peinado R., Growth and yield models for Pinus halepensis Mill., Investig. Agrar. Sis. Recur. For. 10 (2001) 179-202.

[34] Montes F., Sánchez M., Del Rio M., Cañellas I., Using historic management records to characterize the effects of management on the structural diversity of forests, For. Ecol. Manage. 207 (2005) 279-293.

[35] Montoya J.M., Los alcornocales, S.E.A., Madrid, 1988.

[36] Natural Cork Quality Council Industry statistics, Natural Cork Quality Council, Sebastopol, CA, USA, 1999, Online at http://corkqc.com

[37] Oliveira G., Martins-Loução M.A., Correira O. The relative importance of cork harvesting and climate fore stem radial growth of Quercus suber L., Ann. For. Sci. 59 (2002) 439-443.

[38] Sánchez-González M., Tomé M., Montero G., Modelling height and diameter growth of dominant cork oak trees in Spain, Ann. For. Sci. 62 (2005) 1-11.

[39] Sánchez-Palomares O., Sánchez Serrano F., Carretero Carrero M.P., Modelos y cartografía de estimaciones climáticas termopluviométricas para la España peninsular INIA, col. Fuera de Serie, Madrid, 1999.

[40] Searle S.L., Casella G., McCulloch C.E., Variance components, John Wiley \& sons, Inc, New York, 1992, 501 p.

[41] Singer J.D., Using SAS PROC MIXED to fit multilevel models, hierarchical models, and individual growth models, J. Educational Behavioural Statistics 23, (1998) 323-355.

[42] Tomé M., Coelho M. B., Almeida A., Lopes, F., O modelo SUBER. Estrutura e equações utilizadas, Relatórios técnicocientíficos do GIMREF n ${ }^{\circ}$ 2/2001, Centro de Estudos Florestais, Instituto Superior de Agronomia, Lisboa, 2001

[43] Torres E., Montero G., Suarez M.A., Relación entre la densidad de la mas y la producción de corcho en montes alcornocales del sur de España, in: Puertas F., Rivas M. (Eds), II Congreso Forestal Nacional, Tomo IV, 1997, pp. 529-534.

[44] Vazquez F.J., Modelos preditivos de produçao de cortiça e detecçao precoce da qualidade, Ph.D. thesis, ISA, Lisboa, 2002

[45] Vieira Natividade J., Subericultura, D.G.F.P., Lisboa, 1950.

[46] Vonesh E.F., Chinchilli V.M., Linear and nonlinear models for the analysis of repeated measurements, Marcel Dekker, Inc., New York, 1997. 